\title{
ECOLOGICAL FITNESS OF TRIBENURON METHYL (ALS- INHIBITOR HERBICIDE) SUSCEPTIBLE AND RESISTANT BIOTYPES OF WILD MUSTARD IN COMPETITION WITH WHEAT
}

\author{
Haghighi, A. ${ }^{1}$ - Mohamaddoust Chamanabad, H. R. ${ }^{1^{*}}-$ ZAND, $^{2}{ }^{2}-$ Biabani, A. $^{3}-$ \\ ASGHARI, A. ${ }^{1}$ \\ ${ }^{I}$ Department of Agronomy and Plant Breeding, Faculty of Agriculture and Natural Resource, \\ University of Mohaghegh Ardabili, Ardabil, Iran \\ (phone: +98-911-179-3043-A. H.; +98-914-304-2117-A. A.) \\ ${ }^{2}$ Iranian Research Institute of Plant Protection, Agricultural Research, Education and \\ Extension Organization, AREEO, Tehran, Iran \\ (phone: +98-912-300-3132) \\ ${ }^{3}$ Department of Agronomy and Plant Breeding, Faculty of Agriculture, Gonbad-Kavous \\ University, Gonbad-Kavous, Iran \\ (phone: +98-911-374-0583) \\ *Corresponding author \\ e-mail: hr_chamanabad@yahoo.com; phone:+98-915-108-2239 \\ (Received $14^{\text {th }}$ Nov 2018 ; accepted $25^{\text {th }}$ Jan 2019)
}

\begin{abstract}
The occurrence of ALS-herbicide-resistant Sinapis arvensis in wheat crops causes crop yield losses, which makes it necessary to understand the factors that influence the interference of this weed to develop safer management strategies. This study was aimed to evaluate the ecological fitness of wild mustard that is susceptible (S biotypes) and resistant (R biotypes) to Tribenuron Methyl herbicide in competition with wheat in 2014-2017. The experiments were conducted in a greenhouse using a completely randomized design with four replications. The treatments were placed in pots and arranged in replacement series for three experiments: 1 ) wheat with the R biotype; 2 ) wheat with the $\mathrm{S}$ biotype; and 3 ) the $\mathrm{R}$ biotype with the $\mathrm{S}$ biotype) at the following ratios: 100:0, 75:25, 50:50, 25:75, and 0:100. The results showed that $\mathrm{S}$ biotype of wild mustard was more competitive than $\mathrm{R}$ biotype. There was no significant difference between $\mathrm{S}$ biotype and R biotype with accordance of the aggressivity index. The difference between the relative yield of wheat and biotypes of $S$. arvensis was significant, and regarding relative yield total, the $\mathrm{S}$ biotype was superior. Relative seed production index as the resultant index of competition at similar densities was not significant.
\end{abstract}

Keywords: aggressivity index, herbicide resistance, relative yield total, Sinapis arvensis, Triticum aestivum

\section{Introduction}

Since the advent of agriculture, crops have been at risk of weed invasion and damaged quantitatively and qualitatively. Thus, there have been ongoing efforts to reduce the negative impact of weeds on plant production (Vila-Aiub et al., 2015). Wild mustard is one of the most significant weed reducing the quantity and quality of wheat in Iran (Minbashi Moeini et al., 2006). For more than 40 years, relying too much on the technology of herbicides to reduce the amount of damage caused by weed, resulting in obtaining adaptive traits by weeds that help them survive and reproduce under herbicides application condition (Powles and $\mathrm{Yu}, 2010$ ). As a consequence, more than 200 species of resistant weeds have been reported in the world (Heap, 2018) and this 
trend of increasing weed resistance is spreading at a high pace (Norsworthy et al., 2012).

The organisms that genetically earn resistance to some environmental stresses may be ecologically inferior under non-stress conditions compared to susceptible plants (Bazzaz et al., 1987). Theoretically, weed resistance to herbicides is along with fitness cost that has been evaluated in several studies (Van Etten et al., 2016). Fitness cost (which is also called resistance cost) can be defined as reduced fitness of the plant in environments without herbicides (Deyle et al., 2013a). When the fitness costs are created by ecological interferences such as competition, it is termed ecological costs (Vila-Aiub et al., 2009). As an example, Gassmann and Futuyama (2005) stated that resistant plants had less fitness than susceptible plants due to less attraction of pollinators or the increase of pest damage. Also, Vila-Aiub et al. (2009) concluded that resistant plants pay more ecological cost due to the reduced competitiveness to capture resources. Based on the theory of resource allocation, plants show a reaction for the increase in ecological success with the approach of adaptability under environmental selection by directing resources to different organs, i.e. stem and root, and cell metabolism (Van Etten et al., 2016). Resistance due to mutation has been reported to reduce the allocation of resources to growth organs (Vencill et al., 2012). This theory helps to understand the phenomenon "resource trade-off" between plant growth, defensive duties, and reproduction (Coley et al., 1985). When a biotype of weed becomes resistant to herbicide, in most cases, its ability to compete for growth resources decreases (Vila-Aiub et al., 2015). The potential mechanism causing resistance cost is determined with the traits such as the plant size and tolerance to the availability of resources that one of these sources is nitrogen (Frenkel et al., 2017).

Competitive interferences in plants consist of two components: the impact of the plant on the availability of resources and plant response to changes in the availability of resources. Effect of a plant on environmental resources to overcome neighboring plants (competitive effects) or to survive regardless of the competitor's presence (competitive response) depends on the ability of a plant (Goldberg, 1995). Fitness is one of the most effective factors in the creation and persistence of resistant and susceptible biotypes of weeds (Gressel and Segel, 1990; Maxwell et al., 1990). Fitness is defined as the ability of an organism to establish, survive and reproduce successfully (Radosevich et al., 1997). Therefore, the difference between the fitness of $\mathrm{R}$ biotypes and $\mathrm{S}$ biotypes might be due to the difference in survival, fertility (Putwain and Mortimer, 1989), or the ability to compete (Massinga et al., 2005; Marshall et al., 2005).

The reason for estimating the fitness costs about herbicides resistance is that this may reduce the frequency of resistant genotypes in weed communities without herbicide application and it may result in the identification of approaches to managing resistant weeds (Vila-Aiub et al., 2009). The evolution of herbicide resistance in weeds provides an appropriate model to examine the phenomenon "resource trade-off" (development, defense, reproduction) predicted by the theory of resource allocation (Bergelson and Purrington, 1990). Knowing the biological properties of resistant masses and also the mechanisms resulting in resistance may be useful in the management of them (Jordan et al., 1999). Measuring the difference between the fitness of resistant weeds and susceptible weeds, the evolution of resistance to herbicides can be predicted and also, the management strategies can be developed in order to use the traits reducing the ecological traits of resistant masses (Vila-Aiub, et al., 2015). Also, it can be effective in reducing the frequency of resistant plants in the affected population (Gill et al., 1996). 
The difference between the fitness of resistant and susceptible species is an essential factor in predicting the evolution of resistance to the herbicide. In the case of removal of selective pressure of herbicide, if the fitness of resistant plant is less than susceptible plant, the resistant plant is replaced by the susceptible plant (Weiderholt and Stoltenberg, 1996). In this case, after the occurrence of the resistance in weed population, it is hoped that the resistance will be reduced (Zand et al., 2008). However, if this difference is not effective, the frequency of resistant plants will not probably decrease in population, in this case, long-term management of resistant plant needs to adopt the strategies reducing the severity of selection which is desirable for resistant plants and also, needs to combine other management strategies. These strategies are the rational application of herbicides, using the unique biological aspects of resistant weeds and manipulating the farming systems in order to maximize the effectiveness of chemical and non-chemical weed management (Weiderholt and Stoltenberg, 1996). Survival, competitiveness and reproductive success are the criteria of fitness (Massinga et al., 2005). Therefore, this can be performed by performing tests and evaluating the competitive ability and seed production.

As a result, it has been hypothesized that wild mustard has a superior competitive ability than wheat and that there may be differences in the competitiveness among biotypes of wild mustard that are resistant and susceptible to ALS-inhibitor herbicides. Thus, this study aimed to investigate the competitive ability of wheat in coexistence with biotypes of wild mustard that are susceptible and resistant to ALS-inhibitor herbicides and to determine whether there are differences in the competitiveness between the different biotypes.

\section{Materials and methods}

This study consisted of two phases: a) collecting the wild mustard seeds of populations which were suspicious to be resistant to Tribenuron Methyl herbicide from the wheat fields of Golestan Province of Iran and gathering the histories of the fields (Fig. 1) and then, screening the masses and determining their possible resistance in the greenhouse of Agriculture School of Gonbad-Kavous University, Iran (according to Moss et al., 1999).

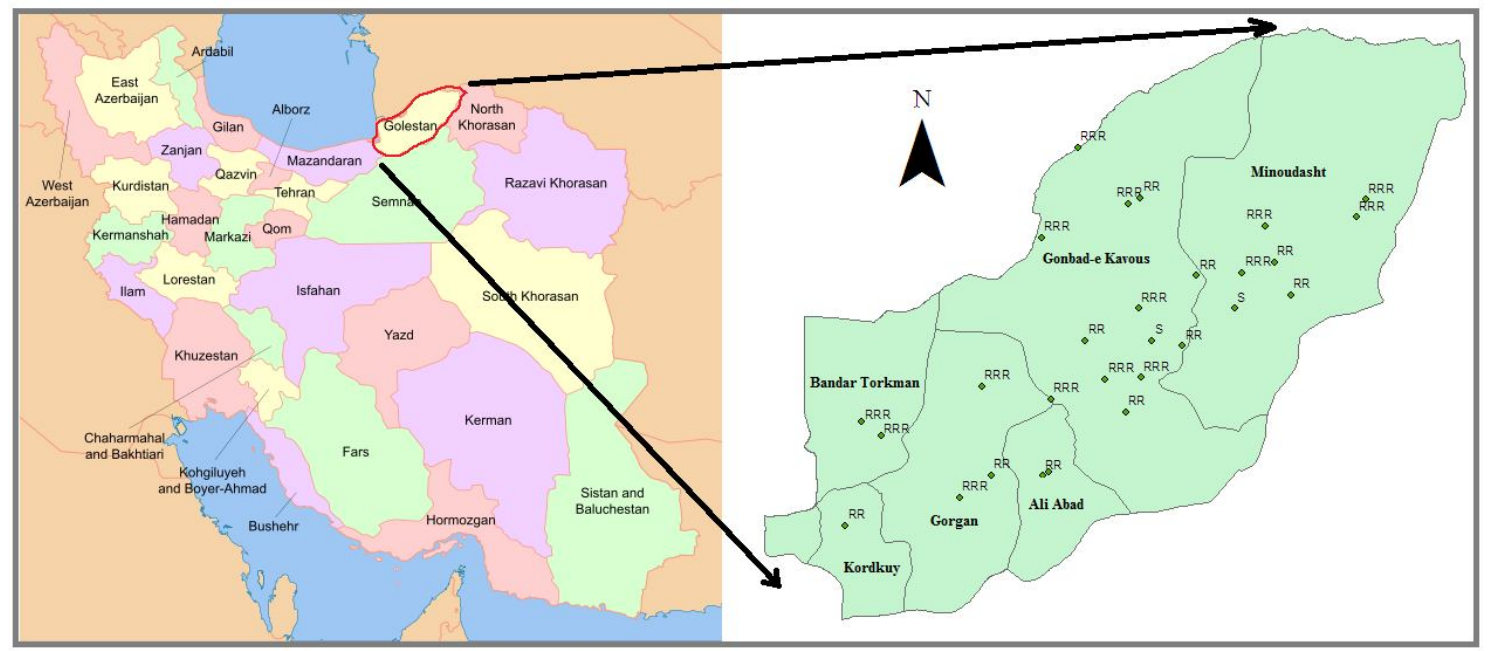

Figure 1. Geographic location and resistance rates of wild mustard seeds 
b) Selecting a resistant biotype (R biotype) along with susceptible biotype (S biotype) and examining the possible relative fitness of them in competition with wheat after identifying the results of screening at Gonbad-Kavous Agricultural Research Station, Iran (Table 1).

Table 1. Specifications of surveyed farms, geographic location and resistance rates based on the Moss method

\begin{tabular}{|c|c|c|c|c|}
\hline $\begin{array}{l}\text { Wild mustard } \\
\text { biotype }\end{array}$ & Longitude & Altitude & $\begin{array}{c}\text { Weight relative to } \\
\text { the control }\end{array}$ & $\begin{array}{l}\text { Resistance type } \\
\text { (Moss et al., 1999) }\end{array}$ \\
\hline Sr-btm & $54-15-59.68$ & $37-0-12.08$ & 0.86 & $\mathrm{RRR}^{*}$ \\
\hline Sr-ems & 54-51-12.97 & $37-6-13.63$ & 0.83 & RRR \\
\hline Sr-aam & $54-36-56-42$ & $37-8-24.62$ & 0.80 & RRR \\
\hline Sr-nsh & $55-9-57.54$ & $37-9-41.02$ & 0.89 & RRR \\
\hline Sr-azs & $54-11-58.76$ & $37-2-33.01$ & 0.88 & RRR \\
\hline Sr-ndm & $54-38-41.30$ & $36-53-36.97$ & 0.27 & $\mathrm{R} ?^{* *}$ \\
\hline Sr-gjn & $54-32-15.33$ & $36-50-0.07$ & 0.78 & RRR \\
\hline Sr-aak & $54-50-44.59$ & $36-54-10.92$ & 0.36 & $\mathrm{RR}^{* * *}$ \\
\hline Sr-fza & $54-49-25.87$ & $36-53-27.28$ & 0.63 & $\mathrm{RR}$ \\
\hline Sr-rmn & $55-6-45.57$ & $37-3-58.45$ & 0.26 & $\mathrm{R} ?$ \\
\hline Sr-kok & $54-8-30.37$ & $36-45-19083$ & 0.36 & $\mathrm{RR}$ \\
\hline Sr-dak & $55-31-22.01$ & $37-26-51.14$ & 0.76 & RRR \\
\hline Sr-Bsh & $55-41-26.47$ & $37-23-5.16$ & 0.50 & $\mathrm{RR}$ \\
\hline Sr-Igr & $55-18-46.16$ & $37-14-49.35$ & 0.41 & $\mathrm{RR}$ \\
\hline Sr-Gzl & $54-57-21.47$ & $37-48-3.77$ & 0.73 & RRR \\
\hline Sr-Gbj & $54-57-40.26$ & $37-15-56.10$ & 0.95 & RRR \\
\hline Sr-Gmt & $55-9-44.70$ & $37-21-9.62$ & 0.87 & RRR \\
\hline Sr-Cpg & $55-7-52.45$ & $37-38-38.55$ & 0.92 & RRR \\
\hline Sr-Ylb & $55-36-15.67$ & $37-34-39.74$ & 0.93 & RRR \\
\hline Sr-Dsb & $54-49-32.29$ & $37-33-2.76$ & 0.90 & RRR \\
\hline Sr-Mrt & $55-55-21.57$ & $37-35-46.68$ & 0.90 & RRR \\
\hline Sr-Gld & $55-57-19.73$ & $37-38-41.57$ & 0.90 & RRR \\
\hline Sr-Blm & $55-2-35.74$ & $37-9-24.27$ & 0.94 & RRR \\
\hline Sr-Kgn & $55-29-42.67$ & $37-20-58.75$ & 0.12 & $\mathrm{~S}^{* * * *}$ \\
\hline Ss-Ykg & $55-38-8.45$ & $37-28-31.77$ & 0.64 & $\mathrm{RR}$ \\
\hline Sr-Agj & $55-21-51.90$ & $37-26-28.49$ & 0.45 & $\mathrm{RR}$ \\
\hline Sr-Abd & $55-10-20.25$ & $37-39-33.10$ & 0.25 & $\mathrm{R}$ ? \\
\hline Ss-Gad & $55-12-24.49$ & $37-15-45.06$ & 0.11 & $\mathrm{~S}$ \\
\hline
\end{tabular}

"RRR: complete resistant, ${ }^{* *} \mathrm{R}$ ?: suspecting resistant, ${ }^{* * *} \mathrm{RR}$ : resistant, ${ }^{* * * *} \mathrm{~S}$ : susceptible

First phase: in June 2014, the seeds of Wild mustard were collected from the fields in which Tribenuron Methyl herbicide was used for at least 7-years by knowing the history of wheat fields. Totally, from each of 28 fields, 500-gram seeds were collected from the parts which were not controlled by Tribenuron Methyl herbicide. The masses of seeds were planted in the pots with the diameter of $30 \mathrm{~cm}$ and depth of $35 \mathrm{~cm}$ in fall in the same year to determine the possible resistance to Tribenuron Methyl herbicide. Firstly, in order to break dormancy, the seeds were treated with $2 \mathrm{mg}$ of Gibberellic acid 
(Abdollahpour et al., 2013). For each biotype, 20 seeds were planted in prepared pots, and they were placed in the open air. After the appearance of true leaves, the density of each pot was reduced to 10 seeds. At 5-7 leaf stage of wild mustard, the common dose of Tribenuron Methyl herbicide (Nezamabadi et al., 2007), $25 \mathrm{~g}$ per hectare (commercial form) was used to determine the possible resistance of masses. According to the method provided by Moss et al. (1999) which is used to determine the resistance in a single dose, the possible resistance of masses was determined. In this method, four weeks after spraying, the live plants of each pot were pruned, and after recording the number of plants, their fresh weight was recorded. With comparing the fresh weight of plant of each mass (Wt) treated by herbicide to the control sample not treated (Wo) with herbicide, the possible resistance was estimated by Equation 1. In the method provided by Moss et al. (1999), less than 36\% reduction, 36-72\% reduction, $72-81 \%$ reduction and $81-100 \%$ reduction in fresh weight are considered as completely resistant (RRR), resistant (R), susceptible to be resistant (R?) and susceptible (S), respectively.

$$
W_{i}=\frac{W_{t}}{W_{o}} \times 100
$$

In screening the collected masses by the mentioned method, $57.14 \%, 25 \%, 10.71 \%$ and $7.14 \%$ of samples were resistant (RRR), resistant (R), susceptible to be resistant (R?) and susceptible (S), respectively. Because of collecting the S biotype to Tribenuron Methyl herbicide from the region of Gonbad-Kavous, the most resistant mass of this region was selected as the $\mathrm{R}$ biotype so that they have least genetic differences, and these biotypes were used to examine the ecological fitness and possible costs of herbicide resistance. 2nd phase: After selecting the seeds, the steps of dormancy breaking and planting in pots were done under the previous method. The experiment was performed in a randomized complete block design with four replications and nine treatments and the form of replacement series in larger pots with a diameter of $40 \mathrm{~cm}$ and a depth of $35 \mathrm{~cm}$. The soil of pots was prepared with a combination of frost soil, manure and washed sand in equal ratios to ensure that there were no seeds of wild mustard. The treatments consisted of $\mathrm{R}$ and $\mathrm{S}$ biotypes of wild mustard and wheat (Triticum aestivum) in replacement ratios of 0:100, 75:25, 50:50, 25:75 and 100:0 (S and $\mathrm{R}$ biotypes of wild mustard and wheat). The total number of pots was 36 (each replication contained nine pots, one pot of wheat, four pots with different densities of $S$ biotype of wild mustard and four pots with different densities of $\mathrm{R}$ biotype of wild mustard). Planting dates were 5th January 2014 and 11th November 2015. After examining the wheat and biotypes of wild mustard physiologically, all of them were pruned, and their dry weight and yield components were measured separately. They were weighted by weighing scales with the accuracy of 0.001 , and the amount of reproduced seeds of wild mustard was estimated by Equation 1. After variance analysis and comparing the means, the indices of competitiveness were used for weeds and crops. With mathematical indices, the features of plant competition, including the intensity of competition and its importance, the effects of competition, reactions, and results of the competition can be examined quantitatively. The indices facilitate the expression and explanation of results, and the results of different studies can be compared by purifying and concentrating the test data (Weigelt and Jolliffe, 2003). Competition indices were divided into three parts of the intensity of competition, the 
impact of competition and the results of the competition. SAS software was used to analyze the data.

$$
S n=T S w \times 50 / S w
$$

Equation 2 was used to determine the amount of reproduced seeds per wild mustard plant (Vila-Aiub et al., 2009). In this equation, $\mathrm{Sn}$ is the number of reproduced seeds per wild mustard plant, TSw is the total weight of reproduced seeds per wild mustard plant, and $\mathrm{Sw}$ is the mean weight of 50 reproduced seeds of wild mustard biotypes.

A) In examining the intensity of competition, the indices of aggressivity and competition ratio were used. In examining the intensity of competition, the changes in the competition of the densities of the population are necessary (Sackville and Hamilton, 2001), so, in all equations related to the intensity of competition, the density was not calculated. However, this does not mean that the intensity of competition is independent of density because, in these indices, the variables depend on the density and frequency naturally (Weigelt and Jolliffe, 2003).

Aggressivity was examined by Equation 3.

$$
A=1 / 2[(\text { Smix } / \text { Wmono })-(\text { Wmix } / \text { Smono })]
$$

Smix: wild mustard at different ratios with wheat

Wmix: wheat at different ratios with $\mathrm{S}$ and $\mathrm{R}$ biotypes

Smono: wild mustard in mono culture

Wmono: wheat in mono culture

Competition ratio was examined by Equation 4.

$$
C R=[\operatorname{Smix} / \text { Smono } / \text { Wmix } / \text { Wmono }]
$$

Smix: wild mustard at different ratios with wheat

Wmix: wheat at different ratios with $\mathrm{S}$ and $\mathrm{R}$ biotypes

Smono: wild mustard in mono culture

Wmono: wheat in mono culture

B) The competition effects of $\mathrm{S}$ and $\mathrm{R}$ biotypes were examine with Relative Yield and Relative Yield Total (Eq. 5).

$$
R Y=\text { Amix } / \text { Amono }
$$

Amix: Different combinations of wheat and wild mustard biotypes

Amono: wheat and $\mathrm{S}$ and $\mathrm{R}$ biotypes in pure culture

C) The outcome of competition was examined by Relative seed production index (Eq. 6).

$$
R R R=S r / S s
$$

Sr: the amount of seeds per resistant wild mustard biotype 
Ss: the amount of seeds per S biotype

Fitness Cost of R biotype to S biotype was examined by (Eq. 7).

$$
F C=1-(W R / W S) \times 100
$$

The analysis of variance, comparison of mean squares and Orthogonal contrasts were performed by SAS software Ver. 9.1 and the figures were designed via Microsoft Excel 2013.

\section{Results}

Results showed that with reduction wild mustard ratio, wild mustard dry weight increased significantly for two biotypes, resulting reduction in wheat dry matter. The reduction of wheat dry matter in competition with biotypes of has been almost uniform and in comparing the $\mathrm{S}$ and $\mathrm{R}$ biotypes was not significant (Fig. 2(A) and Fig. 2(B)). Comparing these two figures showed that this increase of wild mustard dry matter in $\mathrm{S}$ biotype was greater than $\mathrm{R}$ biotype. At same wild mustard ratio, the $\mathrm{S}$ biotype had greater dry matter than $\mathrm{R}$ biotype, and this shows that the increased intraspecific competition in the $\mathrm{S}$ biotype compared to $\mathrm{R}$ biotype.
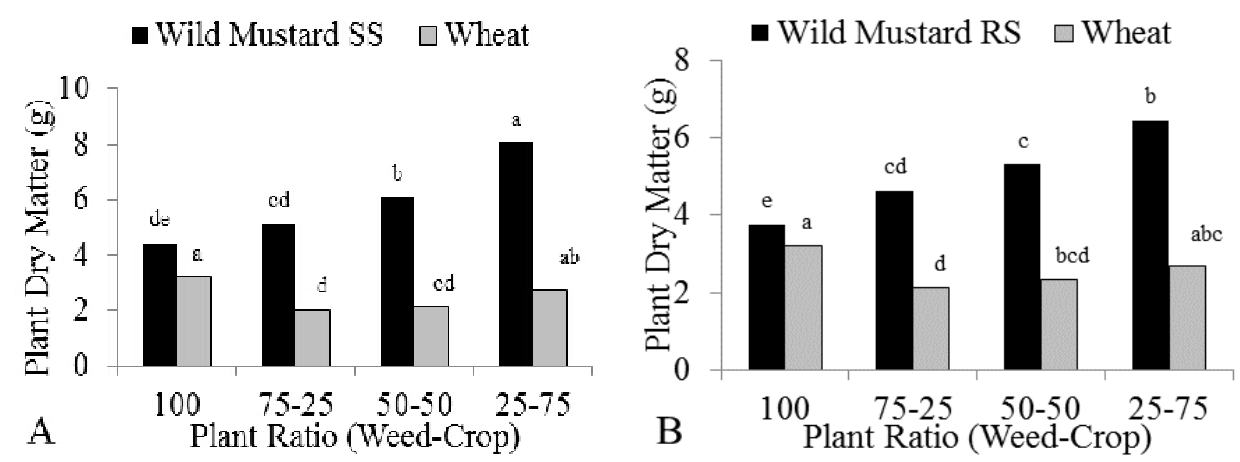

Figure 2. The impression of wheat and wild mustard (A: $S$ biotype, $B: R$ biotype)

As shown in Figure 3, it was observed that the decrease in the number of the wheat spikelet in competition with $\mathrm{S}$ biotype was more than the $\mathrm{R}$ biotype, but the difference was significant only at the 50:50 ratios.
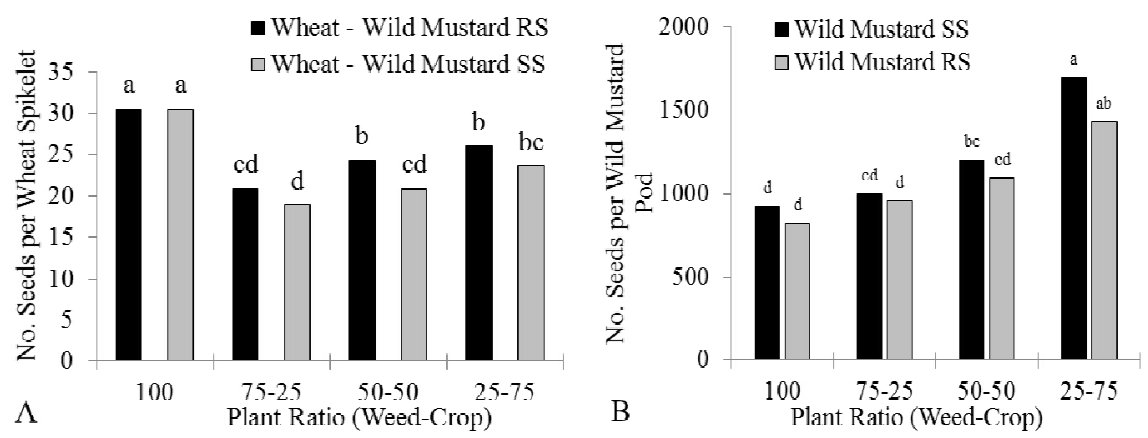

Figure 3. Number of seeds; A: per wheat spikelet in competition with wild mustard, B: number of seeds per wild mustard pod in competition with wheat 
Figure 4 is related to the number of seeds in the biotypes of wild mustard, the difference between these two types of biotypes was not significant at the density ratio of 50:50, but the amount of reproduced seeds in $\mathrm{S}$ biotype was greater than $\mathrm{R}$ biotype.

In accordance the variance analysis of the competition indices (Table 2), it was observed that the differences between the competition ratios of S and R biotypes of wild mustard were significant at the confidence level of 5\% in terms of dry weight, but they were not significant in terms of the number of reproduced seeds. The difference between the indices of aggressivity of $\mathrm{S}$ and $\mathrm{R}$ biotypes of wild mustard was not statistically significant concerning dry weight (Table 2). About wheat, the difference between the relative yields was significant at the confidence level of $5 \%$ and about $\mathrm{S}$ and $\mathrm{R}$ biotypes of wild mustard, it was significant at the confidence level of $1 \%$ (Table 2). The differences between the indices of RYT of S and R biotypes of wild mustard were not statistically significant (Table 2).

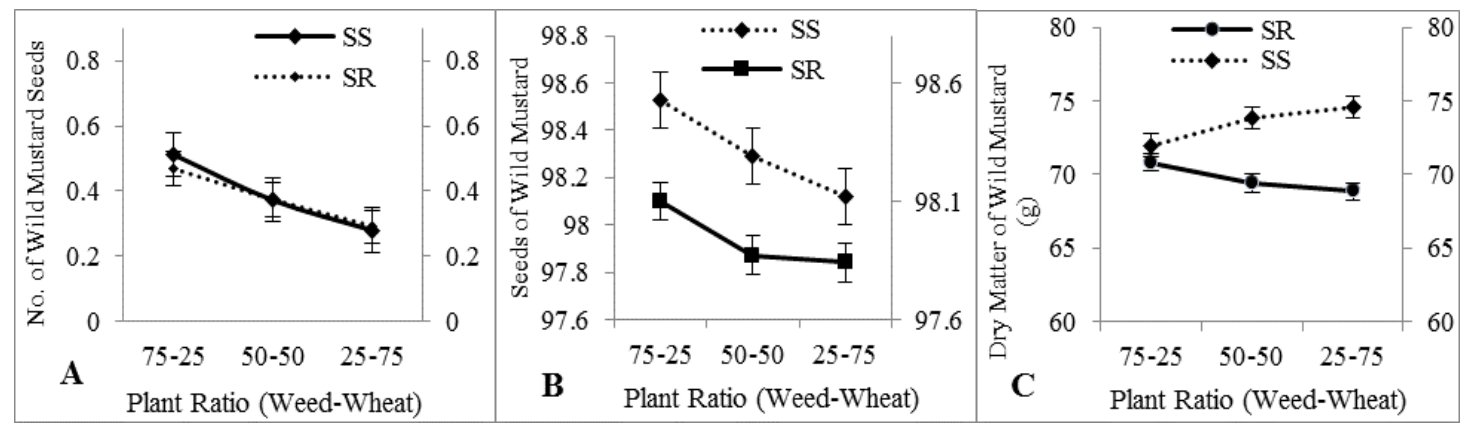

Figure 4. Relative seed reproduction of wild mustard biotypes based on reproduced seeds (A) and competition ratio of wheat and wild mustard biotypes in seed reproduction (B) and dry matter (C)

Table 2. Analysis of variance of competition indices in wild mustard biotypes and wheat at various planting ratios and group comparisons of ratios of $S$ and $R$ wild mustard biotypes with wheat

\begin{tabular}{|c|c|c|c|c|c|c|c|}
\hline Source of variation & $\begin{array}{c}\text { Degree of } \\
\text { freedom }\end{array}$ & $\begin{array}{c}\text { CR }^{1} / \mathrm{dry} \\
\text { matter of } \\
\text { wild } \\
\text { mustard }\end{array}$ & $\begin{array}{l}\text { CR/seed } \\
\text { of wild } \\
\text { mustard }\end{array}$ & $\begin{array}{l}\mathrm{A}^{2} / \text { wild } \\
\text { mustard }\end{array}$ & $\mathrm{RY}^{3} /$ wheat & $\begin{array}{l}\mathrm{RY} / \text { wild } \\
\text { mustard }\end{array}$ & $\begin{array}{c}\mathrm{RYT}^{4} / \text { wild } \\
\text { mustard }\end{array}$ \\
\hline YEAR & 1 & $2.702^{* *}$ & $3.56^{\prime \prime}$ & $0.057^{*}$ & $0.283^{\text {ns }}$ & $1.641 *$ & $1.641^{* *}$ \\
\hline $\mathrm{R}(\mathrm{Y})$ & 6 & $0.071^{*}$ & $0.57^{\mathrm{ns}}$ & $0.002^{\mathrm{ns}}$ & $0.093^{* *}$ & $1.187^{\mathrm{ns}}$ & $4.95^{\mathrm{ns}}$ \\
\hline TREAT & 5 & $0.574^{\mathrm{ns}}$ & $3.93^{*}$ & $0.016^{*}$ & $0.069^{\text {ns }}$ & $3.071^{\mathrm{ns}}$ & $43.21^{*}$ \\
\hline $\mathrm{T}^{*} \mathrm{Y}$ & 5 & $0.056^{\mathrm{ns}}$ & $0.35^{\mathrm{ns}}$ & $0.001^{\mathrm{ns}}$ & $0.089^{\text {ns }}$ & $1.050^{\mathrm{ns}}$ & $4.39^{\mathrm{ns}}$ \\
\hline Error & 30 & 0.269 & 0.34 & 0.006 & 0.069 & 0.93 & 16.07 \\
\hline \multicolumn{2}{|l|}{ C.V. $(\%)$} & 17.21 & 22.60 & 19.54 & 23.19 & 0.31 & 5.60 \\
\hline \multicolumn{8}{|l|}{ Orthogonal contrasts } \\
\hline $\begin{array}{c}(0.75) \mathrm{Ss}+(0.25) \mathrm{W} \\
\text { vs. } \\
(0.75) \mathrm{Rs}+(0.25) \mathrm{W}\end{array}$ & 1 & $1.248^{*}$ & $1.735^{*}$ & $0.04^{*}$ & $0.026^{\text {ns }}$ & $99.5^{*}$ & $0.801^{* *}$ \\
\hline $\begin{array}{c}(0.50) \mathrm{Ss}+(0.50) \mathrm{W} \\
\text { vs. } \\
(0.50) \mathrm{Rs}+(0.50) \mathrm{W}\end{array}$ & 1 & $0.074^{\mathrm{ns}}$ & $0.1008^{\text {ns }}$ & $0.001^{*}$ & $0.146^{* *}$ & $5.3^{\mathrm{ns}}$ & $0.001^{\mathrm{ns}}$ \\
\hline
\end{tabular}




\begin{tabular}{c|c|c|c|c|c|c|c}
\hline $\begin{array}{c}(0.25) \mathrm{Ss}+(0.75) \mathrm{W} \\
\text { vs. } \\
(0.25) \mathrm{Rs}+(0.75) \mathrm{W}\end{array}$ & 1 & $1.476^{*}$ & $2.002^{*}$ & $0.041^{*}$ & $0.077^{*}$ & $107.22^{* *}$ & $2.197^{* *}$ \\
\hline Ss vs.Sr & 1 & $1.414^{*}$ & $0.944^{*}$ & $0.043^{*}$ & $0.025^{* *}$ & $108.33^{*}$ & $1.834^{* *}$ \\
\hline
\end{tabular}

${ }^{1}$ Competition ratio, ${ }^{2}$ Aggressivity, ${ }^{3}$ Relative yield, ${ }^{4}$ Relative yield total. $*$ and $* *$ : significant difference at $1 \%$ and $5 \%$ probability; ns: not significant

Table 3 shows the results of the examination of competition ration based on dry weight. It was observed that the $\mathrm{S}$ biotype was superior to the $\mathrm{R}$ biotype. In the combination of relative densities of S biotype with wheat, with the decrease in the ratio of combination, the competition index increased and with the increase in it, the index reduced. This shows the increase in the intraspecific competition of $\mathrm{S}$ biotype. Nevertheless, in R biotype, in addition to the reduced index, the changes in the ratio in total combination had no significant impact on the competition ratio.

Table 3. Mean comparison of competition parameters on $R$ and $S$ biotypes in different plant ratios

\begin{tabular}{|c|c|c|c|c|c|c|c|}
\hline $\begin{array}{c}\text { Comparison of } \\
\text { mean }\end{array}$ & $\begin{array}{c}\mathrm{CR}^{1} / \mathrm{dry} \\
\text { matter of } \\
\text { wild mustard }\end{array}$ & $\begin{array}{c}\text { CR/seed } \\
\text { of wild } \\
\text { mustard }\end{array}$ & $\begin{array}{l}\mathrm{A}^{2} / \text { wild } \\
\text { mustard }\end{array}$ & $\mathrm{RY}^{3} /$ wheat & $\begin{array}{l}\text { RY/wild } \\
\text { mustard }\end{array}$ & $\begin{array}{c}\mathrm{RYT}^{4} / \text { wild } \\
\text { mustard }\end{array}$ & $\begin{array}{l}\text { RRR/wild } \\
\text { mustard }\end{array}$ \\
\hline$(0.25) \mathrm{Ss}+(0.75) \mathrm{W}$ & $74.58 \mathrm{a}^{5}$ & $98.53 \mathrm{a}$ & $0.512 \mathrm{a}$ & $0.343 \mathrm{c}$ & $3.023 \mathrm{a}$ & $3.36 \mathrm{a}$ & $1.86 \mathrm{a}$ \\
\hline$(0.5) \mathrm{Ss}+(0.5) \mathrm{W}$ & $73.85 \mathrm{a}$ & $98.29 \mathrm{ab}$ & $0.372 \mathrm{ab}$ & $0.357 \mathrm{c}$ & $2.94 \mathrm{ab}$ & $3.29 \mathrm{ab}$ & $1.42 \mathrm{bc}$ \\
\hline$(0.5) \mathrm{Ss}+(0.25) \mathrm{W}$ & $71.98 \mathrm{ab}$ & $98.12 \mathrm{ab}$ & $0.280 \mathrm{~b}$ & $0.393 \mathrm{bc}$ & $2.63 \mathrm{bc}$ & $3.03 \mathrm{bc}$ & $1.105 \mathrm{c}$ \\
\hline$(0.25) \mathrm{Rs}+(0.75) \mathrm{W}$ & $70.83 \mathrm{bc}$ & $98.10 \mathrm{ab}$ & $0.47 \mathrm{a}$ & $0.415 \mathrm{ab}$ & $2.48 \mathrm{~cd}$ & $2.89 \mathrm{c}$ & $1.77 \mathrm{ab}$ \\
\hline$(0.5) \mathrm{Rs}+(0.5) \mathrm{W}$ & $69.41 \mathrm{bc}$ & $97.87 \mathrm{~b}$ & $0.374 \mathrm{ab}$ & $0.444 \mathrm{a}$ & $2.31 \mathrm{~cd}$ & $2.76 \mathrm{c}$ & $1.36 \mathrm{bc}$ \\
\hline$(0.5) \mathrm{Rs}+(0.25) \mathrm{W}$ & $68.86 \mathrm{c}$ & $97.84 \mathrm{~b}$ & $0.290 \mathrm{~b}$ & $0.458 \mathrm{a}$ & $2.28 \mathrm{~d}$ & $2.74 \mathrm{c}$ & $1.20 \mathrm{c}$ \\
\hline LSD & 2.69 & 0.589 & 0.177 & 0.055 & 0.34 & 0.30 & 0.33 \\
\hline
\end{tabular}

${ }^{1}$ Competition ratio, ${ }^{2}$ Aggressivity, ${ }^{3}$ Relative yield, ${ }^{4}$ Relative yield total. ${ }^{5}$ Means within each column followed by the same letter are not significantly different at 0.05 probability level according to LSD

The difference between the aggressivity index of susceptible wild mustard biotype and $\mathrm{R}$ biotype was not significant, but this index in $\mathrm{S}$ biotype was greater than $\mathrm{R}$ biotype. In this index, the degrees of aggressivity of both $\mathrm{S}$ and $\mathrm{R}$ biotypes increased by the reduction in the ratio in total density. The relative yield of wheat was statistically significant at the confidence level of 5\% (Table 3). The relative yield of wheat in combination with $\mathrm{R}$ biotype was greater. At the highest density of $\mathrm{R}$ biotype of wild mustard with wheat (25\%:75\%), the greatest relative yield was obtained. The relative yield of wheat in combination with $\mathrm{S}$ biotype was significantly less than $\mathrm{R}$ biotype. It was observed in $\mathrm{S}$ biotype that with the increase in the ratio of total density for wild mustard, the relative yield of wheat increased. About this index, it can be said that the $S$ biotype in compared with the $\mathrm{R}$ biotype significantly reduced the relative yield of wheat, but with the increase in the density of wild mustard biotypes and also the increase in the intraspecific competition, the relative yield of wheat increased. The difference between the relative yields of wild mustard biotypes was significant at the confidence level of $1 \%$. The differences between the relative yields of S biotype of wild mustard in different combination with wheat were not significant. In orthogonal 
comparisons of Table 3, it was observed that the indices of competition significantly changed with the changes in the ratio of wild mustard biotypes and or wheat at different density ratios. This shows the indirect impact of relative density and total density on the estimation of indices.

However, concerning the S biotype, it was observed that the increase in the ratio of this biotype at the different ratios with wheat reduced the relative yield. The highest relative yield of S biotype was obtained at the ratio of $25 \%$ of total density.

Figure $5 \mathrm{~A}$ shows the fitness cost of $\mathrm{R}$ biotype in seed reproduction and Figure $5 \mathrm{~B}$ shows it in the biological yield. The fitness cost of $\mathrm{R}$ biotype was greater than $\mathrm{S}$ biotype in both cases. Cost of resistance for $\mathrm{R}$ biotype at different intercropping ratios (resistant wild mustard: Wheat) of 100\%: 0\%, 25\%: 75\%, 50\%: 50\% and 75\%: $25 \%$ resulted in $14.73,9.39,12.21,19.67$ percent decrease in biological yield and 4.60, 10.76, 8.71 and 15.75 percent decrease in seed reproduction, respectively.
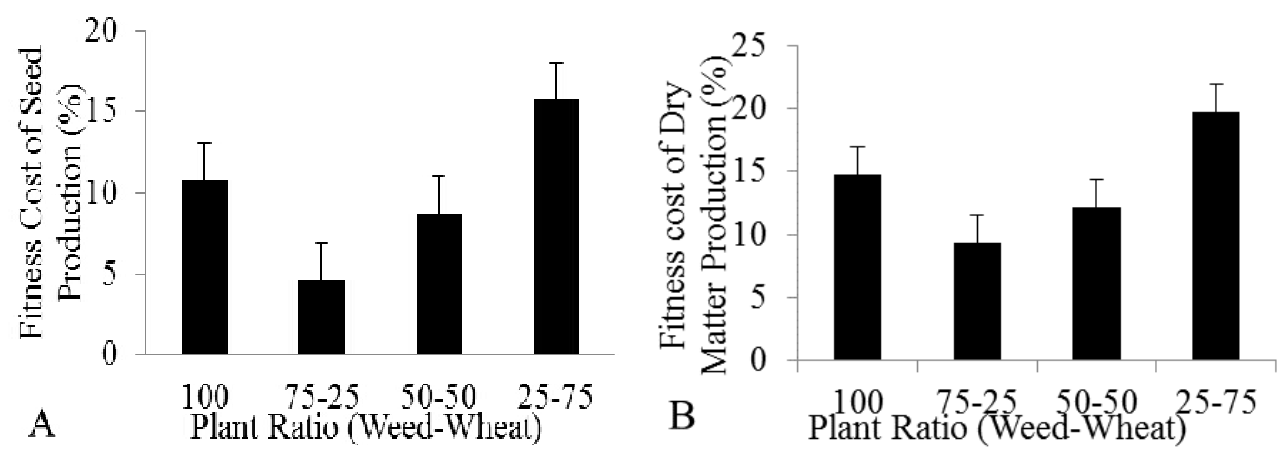

Figure 5. Percentage of the fitness cost of wild mustard $R$ biotype in seed reproduction (A), and dry mass production $(B)$

\section{Discussion}

The results of this study showed that the ecological costs are related to the resistance of wild mustard to Tribenuron Methyl herbicide. The $\mathrm{R}$ biotype of wild mustard in competition with wheat had fewer damages compared to $\mathrm{S}$ biotype (competitive effects). Besides, the capacity of vegetative and reproductive resource allocation in competition with wheat (competitive reaction) in $\mathrm{R}$ biotype was significantly less than $\mathrm{S}$ biotype. The ecological costs related to the herbicide resistance were in line with the theory of resource allocation that predicts a negative correlation between plant growth and resistance to environmental stresses (Bazzaz et al., 1987; Lerdau and Gershenzon, 1997). Also, the results of this study showed that in conditions of intense competition, the cost of herbicide resistance is higher (Figs. 1 and 2). In the higher ratios of wild mustard, the amount of dry matter of $\mathrm{R}$ biotypes was less than $\mathrm{S}$ biotype. In competition with wheat, $\mathrm{S}$ and $\mathrm{R}$ biotypes of wild mustard showed different effects. Conard and Radosevich (1979) found dry matter production of S biotypes (Senecio vulgaris and Amaranthus retroflexus) was higher than that of $\mathrm{R}$ biotypes, under both competitive and non-competitive conditions. Costa and Rizzardi (2014) also reported that R and S biotypes of Raphanus raphanistrum significantly decreased the wheat shoot dry matter.

Results showed that in the intense competition, R biotype has less fitness than $\mathrm{S}$ biotype in attracting resources. This result is consistent with the result of the study by Herms and Mattson (1994) that believed the cost of resistance increases regarding 
resource constraints. The ability of a plant to reduce the growth of neighboring plants (competitive effect) and to continue to grow despite the presence of neighboring plants (competitive reaction) depends on the capacity of attracting resources (Goldberg, 1995). Such processes, which are related to the difference in the amount of dry matter of the plant height, the potential ability of a plant to attract the light and the continuation of this positive feedback, result in disproportionate resources allocation. Ranking competitive effects based on the ability to reduce the growth of targeted species is associated with ranking the maximum potential of measures between $\mathrm{R}$ and $\mathrm{S}$ biotypes. So, the larger plants, i.e., $\mathrm{S}$ biotypes, overcome the wheat with greater power. In nature, due to this problem, the $\mathrm{S}$ biotypes overcome the $\mathrm{R}$ biotypes over a long time. This result is consistent with the results of other studies on different competitive effects of plant species in terms of plant size (Goldberg, 1995).

The results showed that intraspecific competition between the $\mathrm{S}$ biotypes was more than $\mathrm{R}$ biotypes. By accepting that the capacity of attracting the resources is greatly related to the size of a plant, it can be predicted that competitive effects and reaction will have a positive correlation with larger plants and they will have more competitive reactions than smaller plants (Goldberg, 1995). In conditions of competition with wheat, $\mathrm{S}$ biotypes clearly showed more competitive reaction than the $\mathrm{R}$ biotypes, and this resulted in more reduction in wheat dry matter and yield. Different tolerance to low levels of resources can result in different competitive reactions between $\mathrm{S}$ and $\mathrm{R}$ biotypes. This potential ability of $\mathrm{S}$ biotype to continue the growth regarding resources constraints may appear in the conditions in which there is intense competition for resources. For example, the competitive effects of wheat on $\mathrm{R}$ biotype were more compared to $\mathrm{S}$ biotype. Its signs can be observed in the effects of vegetative and reproductive organs of $\mathrm{R}$ biotype compared to $\mathrm{S}$ biotype. The differences in the dry matter of targeted plant showed that the competitive reaction of $\mathrm{R}$ biotypes might appear concerning intense competition or significant environmental resource constraints. In the diminished competitive reaction for resources is related to the effect of herbicide resistance, it can reduce the fitness of plant that finally will result in a reduction in $\mathrm{R}$ biotype compared to $\mathrm{S}$ biotype with natural selection. Therefore, this fitness cost in keeping genetic polymorphism is related to the herbicide resistance (Antonovics and Thrall, 1994). Despite the diminished ability of $\mathrm{R}$ biotypes in competition with wheat, herbicide resistant plants showed poor intraspecific competition with the capacity of growth continuation in response to different cultures. This may be related to poor intraspecific competition due to the smaller size. Stoll and Prati (2001) reported that less intraspecific spatial density might be an approach to advance the survival of weaker competitors ( $\mathrm{R}$ biotype) compared to stronger competitors (S biotype) and also, to prevent the replacement. Vila-Aiub et al. (2009) believed that apart from the concept of evolution of herbicide resistance, the intensity of selective pressure that is caused by humans can change the approaches in the history of plant life during only a few generations. These approaches are different methods of resources allocation in growth, defense, and reproduction models. Now, it is proved that revolutionary changes can earn a place on ecological time scales (Carrol et al., 2007) and this process can be accelerated by human activities (Palumbi, 2001). 


\section{Conclusion}

The results showed that the $\mathrm{R}$ biotype of wild mustard caused significant damage to dry weight and economic yield of wheat, although the damage was less than the $\mathrm{S}$ biotype. The trend of variations in the dry weight of resistant and susceptible wild mustard biotypes at different ratios of density showed that the intra-specific competition in the resistant biotype was higher than that of the susceptible biotype. The competitive indices and relative yield of susceptible biotypes of wild mustard were higher than those of resistant biotypes, but the invasive index was not significant. Seed production of the resistant biotype was lower than that of the susceptible biotype of wild mustard, but since the seed production of this weed is very high, this biological characteristic of the $\mathrm{R}$ biotype could hardly be used for short-term management of this weed. Due to the fact that the frequency of resistant wild mustard plants in the short term will not be reduced because of reduced fitness cost, the use of integrated methods such as chemical, agronomic and mechanical ones, along with the use of biological and ecological aspects, could be used as a strategy to reduce the population of wild mustard R biotype. It is suggested that the ecological dynamics and fitness cost of wild mustard $\mathrm{R}$ and $\mathrm{S}$ biotypes should be investigated in infected fields, both practical and long-term.

\section{REFERENCES}

[1] Bazzaz, F. A., Chiariello, N. A., Coley, P. D., Pitelka, L. F. (1987): Allocating resources to reproduction and defense. - Biosience 37: 58-67.

[2] Bergelson, J., Purrington, C. B. (1995): Surveying patterns in the cost of resistance in plants. - American Naturalist 148: 536-558.

[3] Carrol, S. P., Hendry, A. P., Reznick, D. N., Fox, C. W. (2007): Evolution on ecological time scales. - Functional Ecology 21: 387-393.

[4] Chapin, F. S., Autumn, K., Pugnaire, F. (1990): Evolution of suites of traits in response to environmental-stress. - American Naturalist 142: 278-292.

[5] Coley, P. D., Bryant, J. P., Chapin, F. S. (1985): Resource availability and plant antiherbivore defense. - Science 230: 895-899.

[6] Conard, S. G., Radosevich, S. R. (1979): Ecological fitness of Senecio vulgaris and Amaranthus retroflexus biotypes susceptible or resistant to atrazine. - Journal of Applied Ecology 16: 171-177. DOI: 10.2307/2402736.

[7] Costa, L. O., Rizzardi, M. A. (2014): Resistance of Raphanus raphanistrum to the herbicide metsulfuron-methyl. - Planta Daninha 32(1): 181-187. http://dx.doi.org/10.1590/S0100-83582014000100020.

[8] Delye, C., Jasieniuk, M., Le Corre, V. (2013): Deciphering the evolution of herbicide resistance in weeds. - Trends Genetics 29: 649-658.

[9] Frenkel, E., Matzrafi, M., Rubin, B., Peleg, Z. (2017): Effects of environmental conditions on the fitness penalty in herbicide resistant Brachypodium hybridum. Frontiers in Plant Science 8: 94-105. DOI: 10.3389/fpls.2017.00094.

[10] Gassmann, A. J. Futuyma, D. J. (2005): Consequence of herbivore for the fitness cost of herbicide resistance: photosynthetic variation in the context of plant-herbivore interaction. - Journal of Evolutionary Biology 18: 447-454.

[11] Gill, G. S., Cousense, R. D. Allan, M. R. (1996): Germination, growth and development of herbicide resistant and susceptible population of rigid ryegrass (Lolium rigidum). Weed Science 44: 252-256.

[12] Goldberg, D. E. (1995): Components of Resource Competition in Plant Communities. In: Grace, J. B., Tilman, D. (eds.) Perspectives in Plant Competition. Academic Press, San Diego, pp. 27-49. 
[13] Gressel, J., Segel, I. A. (1990): Modeling the effectiveness of herbicide rotation and mixtures as strategic to delay orto percule resistance. - Weed Technology 4: 186-195.

[14] Heap, I. M., 2018. The International Survey of Herbicide Resistant Weeds. www.weedscience. org (accessed Nov 24, 2018).

[15] Herms, D. A. Mattson, W. J. (1994): Plant-growth and defense. - Trends in Ecology Evolution 9: 488-498.

[16] Jordan, N., Kelrick, M., Brooks, J., Kinerk, W. (1999): Biorational management tactics to select a gimst triazine-resistant Amaranthus hybridus: a field trial. - Journal of Applied Ecology 36: 123-13.

[17] Lerdau, N., Gershenzon, J. (1997): Allocation Theory and Chemical Defense. - In: Bazzaz, F., Grace, T. (eds.) Plant Resource Allocation. Academic Press, London.

[18] Marshall, M., Khatib, K., Loughin, T. (2005): Gene flow, growth, and competitiveness of imazethapyr resistant common sunflower. - Weed Science 49: 14-21.

[19] Massinga, R. A. M., Al-Khatib, K. P., Amand, S. T., Miller, J. F. (2005): Relative fitness of imazamox-resistant common sunflower and prairie sunflower. - Weed Science 53: 166-175.

[20] Maxwell, B. D., Roush, M. L., Radosevich, S. R. (1990): Predicting the evolution and dynamics of herbicide resistance in weed populations. - Weed Technology 4: 2-13.

[21] Minbashi Moeini, M., Nezamabadi, N., Zand, E. (2007): Analysis approach for weed management of irrigated wheat fields. - Key articles of 2nd Conference on Weeds in Iran, 30th and 31th October, Mashhad.

[22] Moss, S. R., Clarke, J. H., Blair, A. M. Culley, T. N. Read, M. A. Ryan, P. J., Turner, M. (1999): The occurrence of herbicide-resistant grass-weeds in the United Kingdom and a new system for designating resistance in screening assay. - Proceeding of the Brighton Crop Protection Conference on Weeds. BCPC, Hampshire, UK, 179-184.

[23] Nezamabadi, N., Zand, E., Pourazar, R., Baghestani Torshiz, N., Baghestani Meybodi, M. A. (2007): Dose-response of the number of broadleaf weeds in wheat fields to different formulations of Tribenuron Methyl herbicide. - Journal of Pajouhesh va Sazandegi 74: 99-107.

[24] Norsworthy, J. K., Ward, S. M., Shaw, D. R., Llewellyn, R. S., Nichols, R. L., Webster, T. M., Bradley, K. W., Frisvold, G., Powles, S. B., Burgos, N. R., Witt, W. W., Barrett, M. (2012): Reducing the risks of herbicide resistance: best management practices and recommendations. - Weed Science 60: 31-62. http://dx.doi.org/10.1614/WS-D-1100155.1.

[25] Palumbi, S. R. (2001): Evolution humans as the world's greatest evolutionary force. Science 293: 1786-1790.

[26] Powles, S. B., Yu, Q. (2010): Evolution in action: plants resistant to herbicides. - Annual Review of Plant Biology 61: 317-347.

[27] Putwain, P. D., Mortimer, A. M. (1989): The resistance of weeds to herbicides: Rational approaches for containment of a growing problem. - Proceedings of the Brighton Crop Protection Conference - Weeds, pp. 432-438.

[28] Radosevich, S., Holt, J. Ghersa, C. (1997): Weed Ecology, Implications for Management. 2nd Ed. - John Wiley and Sons, Inc., New York.

[29] Stoll, P., Prati, D. (2001): Interference aggregation alters competitive interactions in experimental plant communities. - Ecology 82: 319-327.

[30] Van Etten, M. L., Kuester, A., Chang, S. M., Baucom, R. S. (2016): Fitness costs of herbicide resistance across natural populations of the common morning glory, Ipomoea purpurea. - Evolution 70: 2199-2210.

[31] Vencill, W. K., Nichols, R. L., Webster, T. M., Soteres, J. K., Mallory-Smith, C., Burgos, N. R., Johnson, W. G., McClelland, M. R. (2012): Herbicide resistance: toward an understanding of resistance development and the impact of herbicide-resistant crops. Weed Science 60: 2-30. 


$$
-6240-
$$

[32] Vila-Aiub, M. M., Powles, N. P. (2009): Evidence for one ecological cost of enhanced herbicide metabolism in Lolium rigidum. - Journal of Ecology 97: 772-780.

[33] Vila-Aiub, M. M., Gundel, P. E., Preston, C. (2015): Experimental methods for estimation of plant fitness costs associated with herbicide resistance genes. - Weed Science 63: 203-216.

[34] Weiderholt, R. J., Stoltenberg, D. E. (1996): Absence of differential fitness between Giant foxtail (Setaria faberi) Accessions resistant and susceptible to Acetyl-coenzyme A carboxylase inhibitors. - Weed Science 44(1): 18-24.

[35] Weigelt, A., Jolliffe, P. (2003): Indices of plant competition. - Journal of Ecology 91: 707-720.

[36] Zand, E., Baghestani, M. A., Mousavi, S. K., Oveisi, M., Ebrahimi, M., Rastgoo, M. M., Labbafi Hoseinabadi, R. (2008): Weed Management Guide. - Jahad Daneshgahi Press, Mashhad (in Persian with English summary). 